\title{
Antioxidant activity of ginger extract as a daily supplement in cancer patients receiving adjuvant chemotherapy: a pilot study
}

This article was published in the following Dove Press journal:

Cancer Management and Research

3I January 2017

Number of times this article has been viewed

\author{
Kwanjit Danwilai ${ }^{1,2}$ \\ Jitprapa Konmun 2,3 \\ Bung-orn Sripanidkulchai ${ }^{4}$ \\ Suphat Subongkot ${ }^{2,4,5}$ \\ 'Department of Pharmacy Practice, \\ Faculty of Pharmaceutical Sciences, \\ Naresuan University, Phitsanulok, \\ ${ }^{2}$ The College of Pharmacotherapy of \\ Thailand, Nonthaburi, ${ }^{3}$ Department \\ of Pharmacy, Ramathibodi Hospital, \\ Mahidol University, Bangkok, ${ }^{4}$ Center \\ for Research and Development of \\ Herbal Health Products, ${ }^{5}$ Clinical \\ Pharmacy Division, Faculty of \\ Pharmaceutical Sciences, Khon Kaen \\ University, Khon Kaen, Thailand
}

Purpose: The aim of this study was to examine the antioxidant activity of ginger extract oral supplement in newly diagnosed cancer patients receiving adjuvant chemotherapy compared to placebo.

Patients and methods: Newly diagnosed cancer patients receiving moderate-to-high emetogenic potential adjuvant chemotherapy were randomized to receive either a ginger extract (standardized 6-gingerol $20 \mathrm{mg} /$ day) or a placebo 3 days prior to chemotherapy, which they continued daily. Oxidant/antioxidant parameters, including the activities of superoxide dismutase (SOD) and catalase (CAT) and levels of glutathione peroxidase (GPx), total glutathione (GSH/ GSSG), lipid peroxidation products detected as malondialdehyde (MDA) and $\mathrm{NO}_{2}{ }^{-} / \mathrm{NO}_{3}{ }^{-}$, were measured at baseline and at days 1, 22, 43 and 64 after undergoing chemotherapy. Two-sided statistical analysis, with $P<0.05$, was used to determine statistical significance.

Results: A total of 43 patients were included in the study: 19 and 24 patients were randomly assigned to the ginger group and placebo group, respectively. Antioxidant activity parameters, including SOD, CAT, GPx and GSH/GSSG, were significantly increased at day 64 in the ginger group compared to those in the placebo group, while $\mathrm{MDA}$ and $\mathrm{NO}_{2}{ }^{-} / \mathrm{NO}_{3}{ }^{-}$levels were significantly decreased $(P<0.0001)$. When compared to the baseline, the activities of SOD and CAT and the levels of GPx and GSH/GSSG were significantly higher on day $64(P=0.01)$, while the blood levels of MDA and $\mathrm{NO}_{2}{ }^{-} / \mathrm{NO}_{3}{ }^{-}$were significantly decreased $(P<0.01)$.

Conclusion: Daily supplement of ginger extract started 3 days prior to chemotherapy has been shown to significantly elevate antioxidant activity and reduce oxidative marker levels in patients who received moderate-to-high emetogenic potential chemotherapy compared to placebo.

Keywords: ginger extract, antioxidant activity, emetogenic potential adjuvant chemotherapy

\section{Introduction}

Administration of chemotherapy, particularly anthracyclines, platinum complexes, alkylating agents, epipodophyllotoxins and camptothecins, in cancer patients can potentially generate high levels of reactive oxygen species resulting in an increased degree of oxidative stress. ${ }^{1}$ This is illustrated by the elevation of lipid peroxidation products and nitric oxide (NO) and the marked reduction in the blood levels of antioxidants, for instance, the activities of superoxide dismutase (SOD) and catalase (CAT) and the level of glutathione (GSH). ${ }^{2-4}$ Oxidative stress from chemotherapy is primarily responsible for many adverse effects such as nephrotoxicity, cardiotoxicity, pulmonary toxicity ${ }^{5,6}$ and nausea/vomiting. ${ }^{7}$ Several investigations on herbal medicine antioxidant activity have been conducted to explore pathways that would counteract with oxidative stress and consequently ameliorate chemotherapy side effects.
Correspondence: Suphat Subongkot Clinical Pharmacy Division, Faculty of Pharmaceutical Sciences, Khon Kaen University, 123 Mittraphap Road, Khon Kaen 40002, Thailand

Tel +6643202378

Email supsub2@kku.ac.th 
Ginger (Zingiber officinale Roscoe) is a medicinal plant containing active compound gingerols, which are described by their pungency. ${ }^{8}$ The most abundant pungent component of ginger is 6-gingerol and is claimed to contain antioxidant activity. ${ }^{9}$ Ginger has been widely used to alleviate nausea and vomiting in several settings, for example in patients receiving adjuvant chemotherapy. ${ }^{10-13}$ The primary mechanism of chemotherapy-induced nausea and vomiting (CINV) is related to the production of free radicals within the gastrointestinal tract following the administration of chemotherapy. This leads to the release of neurotransmitters from enterochromaffin cells, which in turn stimulates emesis. ${ }^{7}$ In vitro studies of ginger suggested that the phenolic groups of gingerol component possess antioxidant activity. ${ }^{14}$ Later, animal studies demonstrated that the antioxidant activity of ginger could also increase the activities of CAT and SOD. ${ }^{15}$ The potential renoprotective benefit of 6-gingerol against cisplatin-induced oxidative stress was also observed in Wistar rats. ${ }^{16}$ Similarly, the ethanol extract of ginger could partially protect cisplatininduced oxidative stress and acute renal damage in mice. ${ }^{17}$

To date, there is limited clinical evidence exhibiting the antioxidant activity of ginger in cancer patients receiving chemotherapy. Hence, the principal objective of this study was to examine the antioxidant activity of ginger extract orally administered as a daily supplement in newly diagnosed cancer patients receiving moderate-to-high emetogenic potential chemotherapy.

\section{Patients and methods Study design}

This pilot, randomized, double-blind, placebo-controlled trial was conducted at Ramathibodi Hospital, Bangkok, Thailand, and fully supported by the National Research University and Thailand Research Fund. The participants were randomly assigned into two groups using a block of four randomization techniques. The study coordinator generated a randomization list to assign participants to receive either ginger extract (standardized 6-gingerol) or placebo. The study was approved by the Institutional Review Committee of Faculty of Medicine Ramathibodi Hospital, Mahidol University (No. MUR2012/278) in accordance with the Declaration of Helsinki (1964) and Good Clinical Practice guidelines. Written informed consent was obtained from all the patients before enrollment.

\section{Patients}

Eligible patients (aged $\geq 18$ years with pathologically confirmed newly diagnosed solid tumors, an Eastern Cooperative
Oncology Group [ECOG] performance status 0-2, complete surgical removal of the primary tumor, intended to receive $\geq 3$ consecutive cycles of moderate-to-high emetogenic adjuvant chemotherapy, absolute neutrophil count $\geq 1,500$ cells $/ \mathrm{mL}$, hemoglobin $\geq 10 \mathrm{~g} / \mathrm{dL}$, platelet $\geq 100,000$ cells $/ \mathrm{mL}$, aspartate aminotransferase $[\mathrm{AST}]$ and alanine aminotransferase [ALT] $\leq 2.5$ upper limit of normal, bilirubin $\leq 1.5$ upper limit of normal and creatinine $\leq 1.5$ upper limit of normal) were enrolled. The exclusion criteria consisted of patients who consumed ginger products, warfarin and any appetite stimulants within 2 weeks prior to enrollment or during the study; received neurokinin-1 antagonists; previously received chemotherapy; were pregnant or breastfeeding; had gallstone, hepatitis, or gastrointestinal disease; and had a history of ginger hypersensitivity. All patients were promptly measured for blood levels of oxidant/antioxidant parameters, including the activities of SOD, CAT and glutathione peroxidase (GPx) and levels of total glutathione (GSH/GSSG), $\mathrm{NO}_{2}{ }^{-} / \mathrm{NO}_{3}{ }^{-}$and malondialdehyde (MDA).

\section{Study treatments}

The ginger extract (standardized 6-gingerol) and placebo capsules were manufactured by the Center for Research and Development of Herbal Health Products, Faculty of Pharmaceutical Science, Khon Kaen University, Thailand (petty patent number 10560). A standardized 6-gingerol capsule was composed of ginger extract, referenced as 6-gingerol $5 \mathrm{mg}(1.4 \% \mathrm{w} / \mathrm{w}$ of ginger extract), combined with diluents/binder (microcrystalline cellulose PH 102; Avicel PH 102) and thixotropic thickening (colloidal silicon dioxide). The placebo capsules contained a similar ingredient except ginger extract for matching the weight of the standardized 6-gingerol capsules. The standardized 6-gingerol and placebo capsules were placed into packages of similar color and size. The investigators and participants were blinded to the randomization list and treatment assignments. Patients were randomized to receive either two capsules of standardized 6-gingerol $5 \mathrm{mg}$ or two capsules of placebo twice daily starting from 3 days prior to receiving their first cycle of chemotherapy and continued taking daily through the fourth cycle of chemotherapy. All patients received a standard antiemetic premedication regimen (dexamethasone and ondansetron) 30 minutes prior to the administration of chemotherapy. All patients were eligible to receive rescue antiemetic medications at any time during the study for uncontrolled nausea and/or vomiting per physician's discretion or patient's request. 


\section{Laboratory methods}

\section{Blood sampling}

Blood samples $(10 \mathrm{~mL})$ were drawn from each patient at 5 sampling times: 3 days before receiving ginger extract or placebo and within 24 hours after receiving chemotherapy on days 1, 22, 43 and 64. Blood samples were transferred into tubes containing ethylenediaminetetraacetic acid (EDTA). Each whole blood sample was centrifuged for 15 minutes at $4,000 \times g$ and $4^{\circ} \mathrm{C}$. Plasma was carefully separated into Eppendorf tubes and stored at $-80^{\circ} \mathrm{C}$ until analyzed. After that, buffy coat was removed and discarded, the erythrocytes were washed three times, lyzed with cold distilled water and then stored in a refrigerator at $4^{\circ} \mathrm{C}$ for 15 minutes and centrifuged at $3,000 \times g$ at $4^{\circ} \mathrm{C}$ for 10 minutes for removing cell debris. The supernatant was collected and stored at $-80^{\circ} \mathrm{C}$ until analyzed.

\section{Antioxidant assay}

Erythrocyte CuZn-SOD activity was measured as previously described by Arsova-Sarafinovska et al. ${ }^{18}$ The erythrocyte lysates were diluted 400 -fold with $10 \mathrm{mmol} / \mathrm{L}$ phosphate buffer, $\mathrm{pH}$ 7.0. Each erythrocyte lysate was mixed with a substrate solution containing $0.05 \mathrm{mmol} / \mathrm{L}$ xanthine sodium and $0.025 \mathrm{mmol} / \mathrm{L}$ 2-(4-iodophenyl)-3-(4-nitrophenyl)5-phenyltetrazolium chloride (INT) in a buffer solution containing $50 \mathrm{mmol} / \mathrm{L}$ 3-(cyclohexylamino)-1-propanesulfonic acid (CAPS) and $0.094 \mathrm{mmol} / \mathrm{L}$ EDTA (pH 10.2). Xanthine oxidase $(80 \mathrm{U} / \mathrm{L})$ was added to the mixture, and the increase in absorbance was followed at $505 \mathrm{~nm}$ for 3 minutes. The $\mathrm{CuZn-SOD}$ activity was expressed in units per milliliter.

Erythrocyte GPx activity was measured as previously described by Arsova-Sarafinovska et al. ${ }^{18}$ A reaction mixture of $1 \mathrm{mmol} / \mathrm{L} \mathrm{Na}_{2}$ EDTA, $0.2 \mathrm{mmol} / \mathrm{L}$ nicotinamide adenine dinucleotide phosphate (NADPH), $2 \mathrm{mmol} / \mathrm{L}$ reduced glutathione, $4 \mathrm{mmol} / \mathrm{L}$ sodium azide and 1,000 $\mathrm{U}$ glutathione reductase in $50 \mathrm{mmol} / \mathrm{L}$ Tris buffer ( $\mathrm{pH}$ 7.6) was prepared. Erythrocyte lysate and the reaction mixture (ratio 1:50) were mixed and incubated for 5 minutes at $37^{\circ} \mathrm{C}$. The reaction was initiated by adding $8.8 \mathrm{mmol} / \mathrm{L}$ of hydrogen peroxide, and the decrease in absorbance was recorded at $340 \mathrm{~nm}$ for 3 minutes. The GPx activity was expressed in units per milliliter.

Plasma $\mathrm{NO}_{2}{ }^{-} / \mathrm{NO}_{3}{ }^{-}$concentrations were measured as described by Arsova-Sarafinovska et a ${ }^{18}$ and Tracey et al. ${ }^{19}$ A total of $6 \mu \mathrm{L}$ of plasma was mixed with $44 \mu \mathrm{L}$ of $\mathrm{dH}_{2} \mathrm{O}$, $20 \mu \mathrm{L}$ of $0.31 \mathrm{M}$ phosphate buffer ( $\mathrm{pH} 7.5$ ), $10 \mu \mathrm{L}$ each of $0.86 \mathrm{mmol} / \mathrm{L} \mathrm{NADPH}, 0.11 \mathrm{mmol} / \mathrm{L}$ of flavin adenine dinucleotide (FAD) and $1 \mathrm{U} / \mathrm{mL}$ of nitrate reductase. After the incubation of plasma samples with the reaction mixture for 1 hour at room temperature in the dark, $200 \mu \mathrm{L}$ of Griess reagent (1:1 mixture of $1 \%$ sulphanilamide in $5 \% \mathrm{H}_{3} \mathrm{PO}_{4}$ and $1 \% N$-[1-naphthyl]ethylenediamine) was added to the samples. After a 10-minute incubation period, the absorbance was measured spectrometrically at $540 \mathrm{~nm}$. $\mathrm{NO}_{2}^{-}$ $\mathrm{NO}_{3}{ }^{-}$concentrations were expressed in terms of nanomoles per milliliter.

Erythrocyte CAT activity was measured as previously described by Aebi. ${ }^{20}$ The reaction mixture contained 1:500 dilution of erythrocyte lysates with $50 \mathrm{mM}$ phosphate buffer, $\mathrm{pH}$ 7.0, and $30 \mathrm{mM} \mathrm{H}_{2} \mathrm{O}_{2}$ (ratio 2:1). The decomposition rate of the substrate $\mathrm{H}_{2} \mathrm{O}_{2}$ was monitored spectrophotometrically at $240 \mathrm{~nm}$ for 30 seconds. The activity was expressed as kilounits per milliliter. $1 \mathrm{U}$ is equal to $1 \mu \mathrm{mol}$ of $\mathrm{H}_{2} \mathrm{O}_{2}$ decomposed per minute.

Lipid peroxidation products were determined as thiobarbituric acid reactive substances (TBARS) in terms of MDA in plasma by the method previously described by Premanand et al. ${ }^{21} \mathrm{~A}$ total of $100 \mu \mathrm{L}$ of plasma was added to an Eppendorf tube with $100 \mu \mathrm{L}$ of $0.9 \%$ sodium chloride, $100 \mu \mathrm{L}$ of $20 \%$ trichloroacetic acid (TCA) and $50 \mu \mathrm{L}$ of TBA reagent (200 mg of thiobarbituric acid in $30 \mathrm{~mL}$ of distilled water and $30 \mathrm{~mL}$ of acetic acid) and mixed well. This solution was kept for boiling at $95^{\circ} \mathrm{C}$ for 1 hour. $N$-Butanol was added and mixed well. The Eppendorf tube was centrifuged at 3,000 $\times g$ for 10 minutes. The separated butanol layer was collected and read using a spectrophotometer against reagent blank at $530 \mathrm{~nm}$. TBARS was expressed in terms of nanomole per milliliter.

The level of GSH/GSSG was determined by a glutathione assay kit (catalog number CS0260; Sigma-Aldrich, St Louis, MO, USA). The plasma sample was first deproteinized with $5 \% 5$-sulfosalicylic acid solution, centrifuged to remove the precipitated protein and then assayed for GSH/GSSG level according to the manufacturer's instruction.

\section{Safety assessment}

Toxic effects were assessed according to the Common Toxicity Criteria of the National Cancer Institute (version 4.03).

\section{Statistical analysis}

Normal distribution of data was assured using the Kolmogorov-Smirnov and Shapiro-Wilk tests. Demographic data and patient characteristics were examined descriptively. The categorical data were shown as percentages and frequencies. Normally distributed variables were calculated in terms 
of average (mean) and standard error (SE). Categorical data and numerical data were compared by Pearson's chi-square or Fisher's exact test and independent samples $t$-test, respectively. To estimate longitudinal changes in biochemical values from baseline within group and between groups, the data were carried through a Friedman test. Pairwise comparisons were analyzed by using Wilcoxon signed-rank test. Post hoc test was used to compare mean with Mann-Whitney $U$ test when tests of between groups had a significant effect. A $P$-value $<0.05$ was considered as significant. The SPSS version 17 statistical program (SPSS Inc., Chicago, IL, USA) was used for all statistical analyses.

\section{Results}

From September 2012 to July 2013, 50 patients were enrolled into the study and were randomly assigned to take either standardized 6-gingerol $(n=25)$ or placebo $(n=25)$. Seven patients were excluded from the study: six patients of the ginger group (two patients withdrew consent, one patient was unable to swallow capsule and three patients were referred to other hospitals) and one patient of the placebo group withdrew the consent. A total of 43 patients, including 19 patients of the ginger extract group and 24 patients of the placebo group, were included into the final analysis. Table 1 lists the characteristics of patients. Baseline demographics were well balanced in both groups. The mean age was $52.4 \pm 9.1$ years. All participants were women of whom 39 patients $(91 \%)$ were diagnosed with breast cancer who received anthracycline-based regimen, 24 patients $(56 \%)$ with stage II and 13 patients (30\%) with stage III. In all, $90 \%$ of patients had a good performance status $(\mathrm{ECOG}=0)$. The patient compliance rate to the treatment was $100 \%$.

\section{Biochemical assays}

Oxidant/antioxidant parameters measured within the group (ginger extract and placebo groups) at baseline (3 days prior to treatment) and after the first cycle to fourth cycles of chemotherapy are summarized in Tables 2 and 3 . In patients receiving the ginger extract group on day 64, enzymatic antioxidant activities, including CuZn-SOD, CAT and GPx, and nonenzymatic antioxidant activity (GSH/GSSG) were inclined to increase when compared to those measured at the baseline $(P<0.01)$. Conversely, oxidant parameters, including MDA and $\mathrm{NO}_{2}^{-} / \mathrm{NO}_{3}^{-}$, indicated a decline when compared with those measured at the baseline $(P<0.01)$. Oxidant/antioxidant parameters measured in patients receiving the placebo were inclined to decrease when compared with those measured at the baseline; enzymatic antioxidant
Table I Patients' demographics

\begin{tabular}{|c|c|c|c|c|}
\hline Characteristics & $\begin{array}{l}\text { All } \\
(N=43)\end{array}$ & $\begin{array}{l}\text { Ginger } \\
\text { extract } \\
(n=19)\end{array}$ & $\begin{array}{l}\text { Placebo } \\
(n=24)\end{array}$ & $P$-value \\
\hline Age (year) & & & & 0.74 \\
\hline Mean (SD) & $52.4(9.1)$ & $52.9(8.0)$ & $52.0(10.1)$ & \\
\hline Range & $37-75$ & $4 I-75$ & $37-74$ & \\
\hline Female sex, $\mathrm{n}(\%)^{\mathrm{a}}$ & $43(100)$ & $19(100)$ & $24(100)$ & NA \\
\hline Cancer type, n (\%) & & & & 0.97 \\
\hline Breast cancer & $39(91)$ & $17(90)$ & $22(92)$ & \\
\hline Ovarian cancer & $2(4.5)$ & I (5) & I (4) & \\
\hline Lung cancer & $2(4.5)$ & I (5) & I (4) & \\
\hline \multicolumn{4}{|c|}{ Chemotherapy regimen, $\mathrm{n}(\%)$} & 0.81 \\
\hline \multicolumn{5}{|c|}{ Anthracycline-based regimen } \\
\hline$A C$ & $23(53)$ & $9(47)$ & $14(59)$ & \\
\hline FAC & $15(35)$ & $8(43)$ & $7(29)$ & \\
\hline TAC & I (2) & $0(0)$ & I (4) & \\
\hline \multicolumn{5}{|l|}{$\begin{array}{l}\text { Platinum-based } \\
\text { regimen }\end{array}$} \\
\hline $\begin{array}{l}\text { Cisplatin/ } \\
\text { vinorelbine }\end{array}$ & $2(5)$ & I (5) & I (4) & \\
\hline $\begin{array}{l}\text { Paclitaxel/ } \\
\text { carboplatin }\end{array}$ & $2(5)$ & $\mathrm{I}(5)$ & I (4) & \\
\hline \multicolumn{4}{|c|}{ Emetogenic potential chemotherapy, $n$ (\%) } & 1.00 \\
\hline $\begin{array}{l}\text { Highly emetogenic } \\
\text { potential }\end{array}$ & $4 \mathrm{I}(96)$ & $18(95)$ & $23(96)$ & \\
\hline $\begin{array}{l}\text { Moderately emetogenic } \\
\text { potential }\end{array}$ & $2(4)$ & I (5) & I (4) & \\
\hline Stage of disease, $n(\%)$ & & & & 0.60 \\
\hline 1 & $6(14)$ & $3(16)$ & $3(12)$ & \\
\hline II & $24(56)$ & $9(48)$ & $15(63)$ & \\
\hline III & $13(30)$ & $7(36)$ & $6(25)$ & \\
\hline \multicolumn{4}{|c|}{ ECOG performance status, $n$ (\%) } & 0.58 \\
\hline 0 & $40(93)$ & $17(89)$ & $23(96)$ & \\
\hline $\mathrm{I}$ & $3(10)$ & $2(11)$ & I (4) & \\
\hline
\end{tabular}

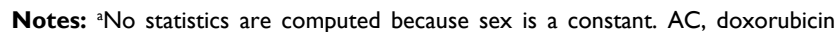
$60 \mathrm{mg} / \mathrm{m}^{2}$ plus cyclophosphamide $600 \mathrm{mg} / \mathrm{m}^{2}$; FAC, doxorubicin $50 \mathrm{mg} / \mathrm{m}^{2}$, cyclophosphamide $500 \mathrm{mg} / \mathrm{m}^{2}$ and 5 -fluorouracil $500 \mathrm{mg} / \mathrm{m}^{2}$; TAC, docetaxel $75 \mathrm{mg} /$ $\mathrm{m}^{2}$, doxorubicin $50 \mathrm{mg} / \mathrm{m}^{2}$ and cyclophosphamide $500 \mathrm{mg} / \mathrm{m}^{2}$.

Abbreviations: NA, not available; ECOG, Eastern Cooperative Oncology Group.

activities, including CuZn-SOD and CAT $(P<0.05)$ and GPx $(P<0.01)$, and nonenzymatic antioxidant activity (GSH/GSSG; $P>0.05$ ). Conversely, oxidant parameters, including $\mathrm{MDA}$ and $\mathrm{NO}_{2}{ }^{-} / \mathrm{NO}_{3}{ }^{-}$, were inclined to increase when compared to those measured at the baseline $(P<0.05$ and $P<0.01$, respectively).

Oxidant/antioxidant parameters compared between the ginger and placebo groups are demonstrated in Figure 1. At day 64, enzymatic antioxidant activities, including CuZn-SOD, CAT and GPx, of the ginger extract group were significantly higher compared to those of the placebo group $(P<0.0001)$. Similarly, the nonenzymatic antioxidant activites (GSH/GSSG) were also significantly elevated in the ginger extract group when compared to those in the placebo group $(P<0.0001)$. MDA and $\mathrm{NO}_{2}{ }^{-} / \mathrm{NO}_{3}{ }^{-}$levels were also 
Table 2 Comparison of the oxidant/antioxidant parameters before and after treatment at four time points in the ginger extract group

\begin{tabular}{llllll}
\hline Parameter & Baseline & Day I & Day 22 & Day 43 & Day 64 \\
\hline CuZn-SOD $(\mathrm{U} / \mathrm{mL})$ & $608.7 \pm 53.6$ & $681.6 \pm 53.6^{\mathrm{b}}$ & $718.3 \pm 55.6^{\mathrm{b}, \mathrm{d}}$ & $752.5 \pm 59.8^{\mathrm{b}}$ & $837.7 \pm 74.9^{\mathrm{b}, \mathrm{c}, \mathrm{e}, \mathrm{g}}$ \\
$\mathrm{CAT}(\mathrm{kU} / \mathrm{mL})$ & $53.5 \pm 2.1$ & $57.4 \pm 1.9^{\mathrm{b}}$ & $60.1 \pm 2.4^{\mathrm{a}}$ & $63.7 \pm 2.5^{\mathrm{b}, \mathrm{c}}$ & $68.1 \pm 3.4^{\mathrm{b}, \mathrm{c}, \mathrm{e}}$ \\
$\mathrm{GPx}(\mathrm{U} / \mathrm{mL})$ & $16.5 \pm 1.2$ & $17.5 \pm 1.2$ & $20.9 \pm 1.2^{\mathrm{a}, \mathrm{d}}$ & $21.4 \pm 0.9^{\mathrm{b}, \mathrm{d}}$ & $23.0 \pm 1.3^{\mathrm{b}, \mathrm{d}, \mathrm{g}}$ \\
$\mathrm{GSH} / \mathrm{GSSG}(\mathrm{nmol} / \mathrm{mL})$ & $18.5 \pm 1.8$ & $19.0 \pm 1.1$ & $20.1 \pm 1.3$ & $21.4 \pm 1.4^{\mathrm{a}, \mathrm{c}, \mathrm{e}}$ & $23.4 \pm 1.3^{\mathrm{b}, \mathrm{d}, \mathrm{f}, \mathrm{h}}$ \\
$\mathrm{MDA}(\mathrm{nmol} / \mathrm{mL})$ & $6.1 \pm 0.2$ & $5.4 \pm 0.1^{\mathrm{a}}$ & $5.1 \pm 0.2^{\mathrm{a}, \mathrm{c}}$ & $5.0 \pm 0.2^{\mathrm{b}}$ & $4.7 \pm 0.2^{\mathrm{b}, \mathrm{d}, \mathrm{e}}$ \\
$\mathrm{NO}_{2}^{-} / \mathrm{NO}_{3}^{-}(\mathrm{nmol} / \mathrm{mL})$ & $24.5 \pm 1.5$ & $21.7 \pm 1.5^{\mathrm{b}}$ & $21.1 \pm 1.8^{\mathrm{a}, \mathrm{d}}$ & $18.2 \pm 1.5^{\mathrm{b}, \mathrm{d}, \mathrm{e}}$ & $17.5 \pm 1.4^{\mathrm{b}, \mathrm{d}, \mathrm{e}}$ \\
\hline
\end{tabular}

Notes: Data are indicated by mean \pm SE. Comparisons were carried out by a Friedman test. Pairwise comparisons used Wilcoxon signed-rank test. ${ }^{\text {a } A s ~ c o m p a r e d ~ w i t h ~}$ baseline, $P<0.05$. ${ }^{b}$ As compared with baseline, $P<0.01$. 'As compared with day I, $P<0.05$. ${ }^{\mathrm{d} A s}$ compared with day I, $P<0.0 \mathrm{I}$. ${ }^{\mathrm{e} A s}$ compared with day $22, P<0.05$. $\mathrm{As}$ compared with day $22, P<0.01$. ${ }^{8}$ As compared with day $43, P<0.05$. ${ }^{\text {h}}$ As compared with day $43, P<0.01$.

Abbreviations: CuZn-SOD, copper zinc superoxide dismutase; CAT, catalase; GPx, glutathione peroxidase; GSH/GSSG, total glutathione; MDA, malondialdehyde; SE, standard error.

Table 3 Comparison of the oxidant/antioxidant parameters before and after treatment at four time points in the placebo group

\begin{tabular}{llllll}
\hline Parameter & Baseline & Day I & Day 22 & Day 43 & Day 64 \\
\hline CuZn-SOD $(\mathrm{U} / \mathrm{mL})$ & $602.6 \pm 43.2$ & $541.9 \pm 36.7^{\mathrm{a}}$ & $505.2 \pm 42.5$ & $478.7 \pm 22.0^{\mathrm{a}}$ & $442.3 \pm 31.6^{\mathrm{a}, \mathrm{c}}$ \\
$\mathrm{CAT}(\mathrm{kU} / \mathrm{mL})$ & $53.7 \pm 2.2$ & $52.0 \pm 2.0$ & $48.9 \pm 2.0^{\mathrm{a}, \mathrm{c}}$ & $46.9 \pm 1.4^{\mathrm{a}, \mathrm{c}, \mathrm{e}}$ & $44.4 \pm 2.3^{\mathrm{a}, \mathrm{e}, \mathrm{e}}$ \\
$\mathrm{GPx}(\mathrm{U} / \mathrm{mL})$ & $16.6 \pm 1.2$ & $15.4 \pm 0.8^{\mathrm{b}, \mathrm{d}}$ & $14.1 \pm 0.7^{\mathrm{b}, \mathrm{c}}$ & $12.8 \pm 1.1^{\mathrm{a}, \mathrm{d}}$ & $10.8 \pm 0.9^{\mathrm{b}, \mathrm{d}, \mathrm{f}}$ \\
$\mathrm{GSH} / \mathrm{GSSG}(\mathrm{nmol} / \mathrm{mL})$ & $18.1 \pm 1.5$ & $17.6 \pm 1.2$ & $17.3 \pm 0.7$ & $16.4 \pm 0.9$ & $15.1 \pm 1.0$ \\
$\mathrm{MDA}(\mathrm{nmol} / \mathrm{mL})$ & $5.9 \pm 0.2$ & $6.1 \pm 0.2^{\mathrm{a}}$ & $6.2 \pm 0.2$ & $6.6 \pm 0.2^{\mathrm{a}}$ & $6.9 \pm 0.3^{\mathrm{a}, \mathrm{c}}$ \\
$\mathrm{NO}_{2} / \mathrm{NO}_{3}^{-}(\mathrm{nmol} / \mathrm{mL})$ & $25.0 \pm 3.6$ & $27.7 \pm 3.4$ & $35.4 \pm 3.8^{\mathrm{a}, \mathrm{c}}$ & $47.5 \pm 3.2^{\mathrm{b}, \mathrm{d}, \mathrm{f}}$ & $55.8 \pm 6.6^{\mathrm{b}, \mathrm{d}, \mathrm{f}}$ \\
\hline
\end{tabular}

Notes: Data are indicated by mean \pm SE. Comparisons were carried out by a Friedman test. Pairwise comparisons used Wilcoxon signed-rank test. ${ }^{a} \mathrm{As}$ compared with baseline, $P<0.05$. ${ }^{\mathrm{A}}$ As compared with baseline, $P<0.01$. 'As compared with day I, $P<0.05$. ${ }^{\mathrm{d} A s}$ compared with day $\mathrm{I}, P<0.0 \mathrm{I}$. ${ }^{\mathrm{e}}$ As compared with day $22, P<0.05$. ${ }^{\mathrm{f}} \mathrm{As}$ compared with day $22, P<0.01$.

Abbreviations: CuZn-SOD, copper zinc superoxide dismutase; CAT, catalase; GPx, glutathione peroxidase; GSH/GSSG, total glutathione; MDA, malondialdehyde; SE, standard error.

showed to decrease in the ginger extract group compared to those in the placebo group $(P<0.0001)$.

\section{Safety assessment}

All 43 patients were monitored for side effects/toxicity reactions throughout the study. None of the patients in the ginger extract group was withdrawn from the study due to unacceptable toxicity. None of patients experienced elevated creatinine greater than upper normal limit at baseline and each follow-up visit. No significant adverse events related to the ginger extract were observed. Three patients experienced AST at baseline greater than the upper normal limit (one patient in the ginger group experienced AST $35 \mathrm{U} / \mathrm{L}$ and two patients in the placebo group experienced AST 35 and $42 \mathrm{U} / \mathrm{L}$ ), but the level of liver function test remained stable at each follow-up visit. One patient in the placebo group experienced grade 1 abnormal AST level compared with that at the baseline (AST 39 vs $25 \mathrm{U} / \mathrm{L}$ ). Five patients experienced ALT at baseline greater than the upper normal limit (three patients in the ginger group experienced ALT 37, 42 and $44 \mathrm{U} / \mathrm{L}$ and two patients in the placebo group experienced ALT 38 and $63 \mathrm{U} / \mathrm{L}$ ), but the level had not changed after monitoring each visit. Five patients had grade 1 abnormal ALT level compared with that at the baseline (two patients in ginger extract group experienced ALT 65 vs $35 \mathrm{U} / \mathrm{L}$ and 42 vs $31 \mathrm{U} / \mathrm{L}$ and three patients in placebo group experienced ALT 59 vs $27 \mathrm{U} / \mathrm{L}$, 59 vs $35 \mathrm{U} / \mathrm{L}$ and 54 vs $26 \mathrm{U} / \mathrm{L}$ ). Two patients experienced abnormal bilirubin at baseline greater than the upper normal limit (one patient in the ginger group and one patient in the placebo group experienced bilirubin $0.4 \mathrm{mg} / \mathrm{dL}$ ).

\section{Discussion}

There have been a number of in vitro ${ }^{14}$ and in vivo studies ${ }^{15-17}$ investigating the antioxidant activity of ginger extract products. Evidence in human subjects is limited, especially in cancer patients. This is a pilot randomized placebo controlled trial on the pharmacological effects of ginger extract in cancer patients who received chemotherapy. The results of our study demonstrated significantly increased antioxidant activity (e.g., CuZn-SOD, CAT, GPX and GSH/GSSG) and decreased oxidative stress (e.g., $\mathrm{NO}_{2}^{-} / \mathrm{NO}_{3}^{-}$and MDA) in patients who received daily ginger extract. This effect was not observed in patients who received placebo, as measured after each chemotherapy cycle. In subsequent cycles of chemotherapy, patients seemed to have significantly elevated oxidative defense status based on their higher blood levels of $\mathrm{Cu}-\mathrm{Zn}$ SOD, CAT, GPx and GSH/GSSG and significantly reduced levels of MDA and $\mathrm{NO}_{2}{ }^{-} / \mathrm{NO}_{3}{ }^{-}$after continuously receiving 


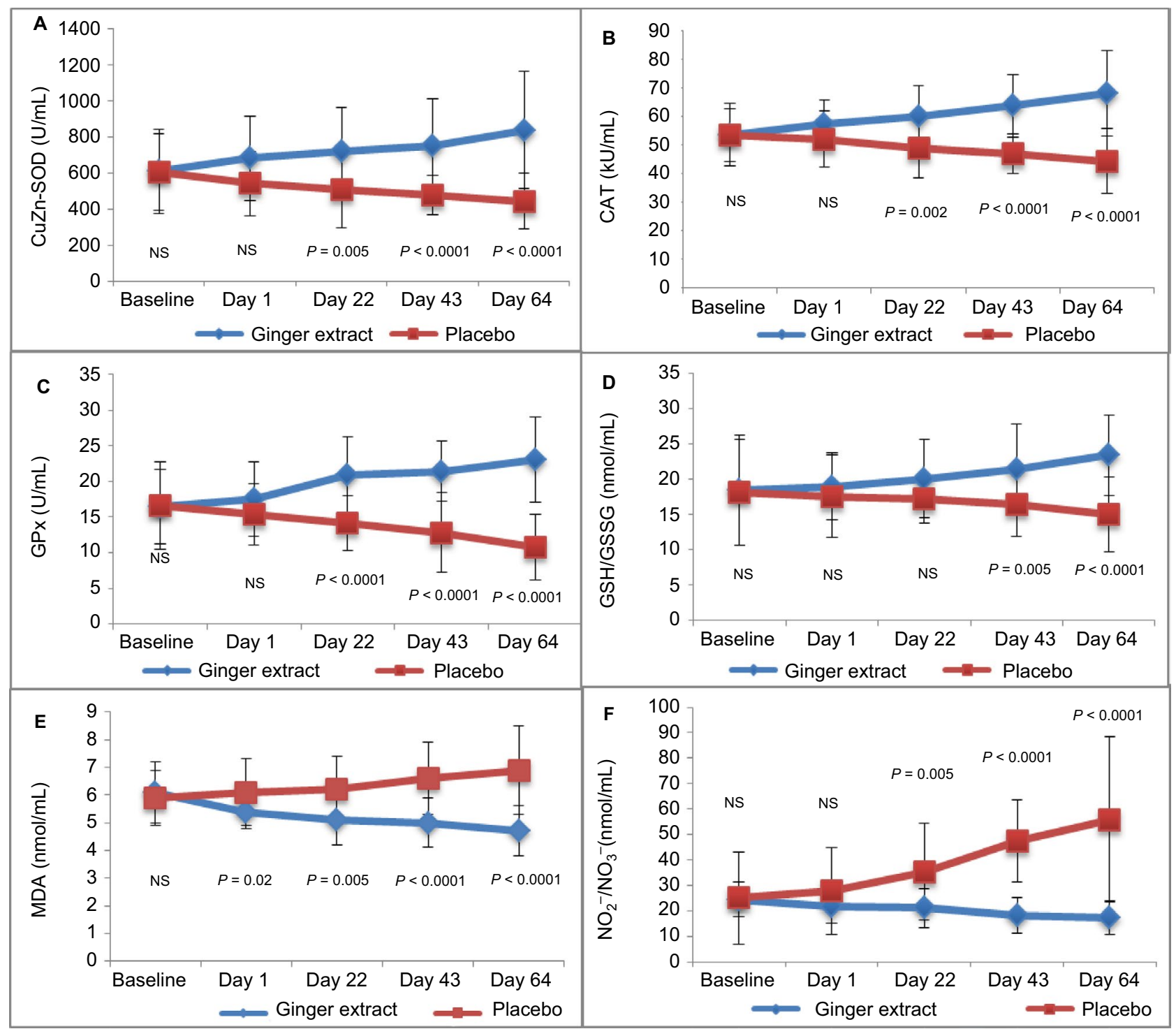

Figure I Oxidant/Antioxidant parameters compare mean (SE) between groups from baseline of patient treated with ginger extract and placebo.

Notes: $P$-values demonstrate statistically significant difference between ginger extract and placebo on each period during the treatment. (A) CuZn-SOD (U/mL), (B) $C A T$ $(\mathrm{kU} / \mathrm{mL}),(\mathbf{C}) \mathrm{GPx}(\mathrm{U} / \mathrm{mL}),(\mathbf{D}) \mathrm{GSH} / \mathrm{GSSG}(\mathrm{nmol} / \mathrm{mL}),(\mathbf{E}) \mathrm{MDA}(\mathrm{nmol} / \mathrm{mL})$ and $(\mathbf{F}) \mathrm{NO}_{2}^{-} / \mathrm{NO}_{3}^{-}(\mathrm{nmol} / \mathrm{mL})$.

Abbreviations: SE, standard error; CuZn-SOD, copper zinc superoxide dismutase; CAT, catalase; GPx, glutathione peroxidase; GSH/GSSG, total glutathione; MDA, malondialdehyde; $\mathrm{NO}_{2}{ }^{-} / \mathrm{NO}_{3}^{-}$, plasma nitrite/nitrate; $\mathrm{NS}$, not significant.

ginger extract. Our study showed similar results with $\omega-3$ fatty acids; after 6 months MDA blood level decreased, while the activity of SOD and level of GPx increased in acute lymphoblastic leukemia (ALL) patients receiving $\omega$-3 fatty acids combined with methotrexate weekly when compared to the baseline or with ALL patients receiving methotrexate weekly alone $(P<0.001) .{ }^{22}$ Similarly, supplementation with vitamin C $500 \mathrm{mg}$ tablet and vitamin E $400 \mathrm{mg}$ gelatin capsule (VCE) once daily in breast cancer patients receiving 5-fluorouracil, doxorubicin and cyclophosphamide showed that VCE supplementation markedly increased the activities of SOD, CAT, glutathione-S-transferase and glutathione reductase as well as of GSH compared with FAC supplementation alone
$(P<0.01)$. There was also a significant reduction in the levels of MDA $(P<0.01){ }^{23}$

Evidence in the literature profusely demonstrates that ginger has strong in vitro and in vivo antioxidant properties. Aqueous and ethanol ginger extract is a significant fountainhead of natural antioxidant. The results indicated that ginger extract had significant scavenging of superoxide radicals and lipid peroxidation. ${ }^{24}$ Another review advocated the effect of 6-gingerol to inhibit NO production. ${ }^{25}$ Daily supplement of ginger powder ( $1 \%$ ginger) for 4 weeks in male albino rats provided significantly raised blood concentrations of GSH/ GSSG. Conversely, ginger powder significantly reduced the MDA blood level. However, the SOD level marginally 
increased and GPx erythrocyte remained unchanged. ${ }^{26}$ In addition, the clinical study reported that early-stage breast cancer patients receiving orally three capsules (each capsule contained $750 \mathrm{mg}$ ) of ginger rhizome powder after six weeks of ginger supplementation showed an increase in GPx $(P=0.002)$, but no statistically significant change was observed in oxidative stress, including MDA and NO, as compared to that before 6 weeks of ginger supplementation. In the ginger group, a statistically significant change was only observed in GPx $(P=0.001)$, as compared to that in the placebo group. ${ }^{27}$ Conversely, the effects of ginger supplementation (1,000 mg of ginger as four capsules daily) for 10 weeks were investigated in patients undergoing continuous ambulatory peritoneal dialysis. No statistically significant change was observed in serum concentrations of MDA in the ginger group compared to that in the placebo group. ${ }^{28}$

Antioxidant supplementation use in patients receiving chemotherapy is a controversial topic. The scientific evidence on this topic is not strongly for or against who should receive antioxidant supplements during chemotherapy. Obviously, interactions between chemotherapy and antioxidants are complex. A limited number of clinical trials have been performed investigating the combination of chemotherapy and antioxidants. Several trials have demonstrated an increase in survival but are limited by their small sample sizes and limited duration. Despite a suggestion of a beneficial effect from these studies, there have been no large randomized long-term clinical trials evaluating the effects of antioxidants administered concomitantly with chemotherapy. ${ }^{29-33}$ More studies are needed to clarify the results of the clinical trials.

In this study, all patients were completely adherent to the protocol. Patient medication compliance was measured by three methods: diary, follow-up phone calls, and pill count. All patients were counseled by a pharmacist prior to taking the assigned medications. Verbal and written product information were provided to all patients. Throughout the study, patients' adherence was followed up by weekly telephone calls, patient diaries and pill counts each visit. The main limitations of our study would be a small sample size and the generalization of results as all of our participants were female. No assessment of the interactions between ginger extract and chemotherapy was performed. We did not observe correlation between the plasma level of 6-gingerol or its metabolites and antioxidant activity to determine the variability in exposure of ginger and compare this to the variability of the measured oxidant/antioxidant parameters. We primarily focused only on measuring the pharmacological antioxidant activity level of ginger extract in this study.
Future studies may need to measure the clinical effect of ginger extract, exploring herbal-drug interaction outcomes (if any). The current systematic review provides preliminary evidence suggesting that certain antioxidant supplements may reduce chemotherapeutic adverse effects. ${ }^{29,33}$ If ginger extract could reduce chemotherapy toxicity for cancer patients, it would be a great benefit and warrant further investigation.

\section{Conclusion}

The present study demonstrates that the ginger extract as a daily supplement for patients receiving moderate-to-high emetogenic adjuvant chemotherapy could increase antioxidant enzyme blood levels, including CuZn-SOD and CAT activity, and levels of GPx and GSH/GSSG and decrease oxidative stress blood levels, including MDA and $\mathrm{NO}_{2}{ }^{-} / \mathrm{NO}_{3}{ }^{-}$, as compared to the placebo. Furthermore, patients taking ginger extract continuously were inclined to increase antioxidant enzyme blood levels and decrease oxidative stress blood level. This result might confirm the antioxidant pharmacological activity of ginger. No serious adverse effects were reported after taking ginger extract as a daily supplement.

\section{Acknowledgments}

This work was supported by the Higher Education Research Promotion and the National Research University Project of Thailand and Office of the Higher Education Commission, through the Food and Functional Food Research Cluster of Khon Kaen University. The authors would like to acknowledge Assistant Professor Youwanush Kongdan; Assistant Professor Ronnarat Suvikapakornkul; Associate Professor Bandit Chunworathayi for patient recruitment at Ramathibodi Hospital, Bangkok, Thailand; Dr. Jeff Johns of Khon Kaen University, Thailand; Mr. Kevin Roebl of Naresuan University Language Centre, Thailand, and Dr. Sirada (Maphanta) Jones of Select Specialty Hospital and University of Wisconsin-Madison School of Pharmacy, USA, for their useful suggestions to the language and structure of the manuscript.

\section{Disclosure}

The authors report no conflicts of interest in this work.

\section{References}

1. Deavall DG, Martin EA, Horner JM, Roberts R. Drug-induced oxidative stress and toxicity. J Toxicol. 2012;2012:13. Article ID 645460.

2. Gupta A, Srivastava S, Prasad R, et al. Oxidative stress in non-small cell lung cancer patients after chemotherapy: association with treatment response. Respirology. 2010;15(2):349-356.

3. Srivastava AN, Gupta A, Srivastava S, et al. Cisplatin combination chemotherapy induces oxidative stress in advance non small cell lung cancer patients. Asian Pac J Cancer Prev. 2010;11(2):465-471. 
4. Amin KA, Mohamed BM, El-wakil MAM, Ibrahem SO. Impact of breast cancer and combination chemotherapy on oxidative stress, hepatic and cardiac markers. J Breast Cancer. 2012;15(3):306-312.

5. Conklin KA. Chemotherapy-associated oxidative stress: impact on chemotherapeutic effectiveness. Integr Cancer Ther. 2004;3(4): 294-300.

6. Fuchs-Tarlovsky V. Role of antioxidants in cancer therapy. Nutrition. 2013;29(1):15-21.

7. Marxa W, Riedb K, McCarthyc AL, et al. Ginger-mechanism of action in chemotherapy-induced nausea and vomiting: a review. Crit Rev Food Sci Nutr. 2017;57(1):141-146.

8. Ali BH, Blunden G, Tanira MO, Nemmar A. Some phytochemical, pharmacological and toxicological properties of ginger (Zingiber officinale Roscoe): a review of recent research. Food Chem Toxicol. 2008;46(2): 409-420.

9. Baliga MS, Haniadka R, Pereirav MM, et al. Update on the chemopreventive effects of ginger and its phytochemicals. Crit Rev Food Sci Nutr. 2011;51(6):499-523.

10. Thamlikitkul L, Srimuninnimit V, Akewanlop C, et al. Efficacy of ginger for prophylaxis of chemotherapy-induced nausea and vomiting in breast cancer patients receiving adriamycin-cyclophosphamide regimen: a randomized, double-blind, placebo-controlled, crossover study. Support Care Cancer. 2017;25(2):459-464.

11. Ansari M, Porouhan P, Mohammadianpanah M, et al. Efficacy of ginger in control of chemotherapy induced nausea and vomiting in breast cancer patients receiving doxorubicin based chemotherapy. Asian Pac $J$ Cancer Prev. 2016;17(8):3877-3880.

12. Ryan JL, Heckler CE, Roscoe JA, et al. Ginger (Zingiber officinale) reduces acute chemotherapy-induced nausea: a URCC CCOP study of 576 patients. Support Care Cancer. 2012;20(7):1479-1489.

13. Lete I, Allué J. The effectiveness of ginger in the prevention of nausea and vomiting during pregnancy and chemotherapy. Integr Med Insights. 2016;11:11-17.

14. Khanom F, Kayahara H, Hirota M, Tadasa K. Superoxide scavenging and tyrosinase inhibitory active compound in ginger (Zingiber officinale Roscoe). Pak J Biol Sci. 2003;6(24):1996-2000.

15. Prakash UN, Srinivasan K. Gastrointestinal protective effect of dietary spices during ethanol-induced oxidant stress in experimental rats. Appl Physiol Nutr Metab. 2010;35(2):134-141.

16. Kuhad A, Tirkey N, Pilkhwal S, Chopra K. 6-Gingerol prevents cisplatininduced acute renal in rats. Biofactors. 2006;26(3):189-200.

17. Ajith TA, Nivitha V, Usha S. Zingiber officinale Roscoe alone and in combination with alpha-tocopherol protect the kidney against cisplatin-induced acute renal failure. Food Chem Toxicol. 2007;45(6): 921-927.

18. Arsova-Sarafinovska Z, Eken A, Matevska N, et al. Increased oxidative/ nitrosative stress and decreased antioxidant enzyme activities in prostate cancer. Clin Biochem. 2009;42(12):1228-1235.
19. Tracey WR, Tse J, Carter G. Lipopolysaccharide-induced changes in plasma nitrite and nitrate concentrations in rats and mice: pharmacological evaluation of nitric oxide synthase inhibitors. JPharmacol Exp Ther. 1995; 272(3):1011-1015.

20. Aebi H. Catalase in vitro. Methods Enzymol. 1984;105:121-126.

21. Premanand R, Kumar S, Mohan A. Study of thiobarbituric reactive substances and total reduced glutathione as indices of oxidative stress in chronic smokers with and without chronic obstructive pulmonary disease. Indian J Chest Dis Allied Sci. 2007;49(1):9-12.

22. Elbarbary NS, Ismail EA, Farahat RK, El-Hamamsy M. $\omega-3$ fatty acids as an adjuvant therapy ameliorates methotrexate-induced hepatotoxicity in children and adolescents with acute lymphoblastic leukemia: a randomized placebo-controlled study. Nutrition. 2016;32(1):41-47.

23. Suhail N, Bilal N, Khan HY, et al. Effect of vitamins C and E on antioxidant status of breast-cancer patients undergoing chemotherapy. J Clin Pharm Ther. 2012;37(1):22-26.

24. Morakinyo AO, Oludare GO, Aderinto OT, Tasdup A. Antioxidant and free radical scavenging activities of aqueous and ethanol extracts of Zingiber officinale. Biol Med. 2011;3(5):25-30.

25. Semwal RB, Semwal DK, Combrinck S, Viljoen AM. Gingerols and shogaols: important nutraceutical principles from ginger. Phytochemistry. 2015;117:554-568.

26. Ahmed RS, Suke SG, Seth V, Chakraborti A, Tripathi AK, Banerjee BD. Protective effects of dietary ginger (Zingiber officinales Rosc.) on lindaneinduced oxidative stress in rats. Phytother Res. 2008;22(7):902-906.

27. Karimi N, Roshan VD. Change in adiponectin and oxidative stress after modifiable lifestyle interventions in breast cancer cases. Asian Pac J Cancer Prev. 2013;14(5):2845-2850.

28. Imani H, Tabibi H, Najafi I, Atabak S, Hedayati M, Rahmani L. Effects of ginger on serum glucose, advanced glycation end products, and inflammation in peritoneal dialysis patients. Nutrition. 2015;31(5):703-707.

29. Block KI, Koch AC, Mead MN, Tothy PK, Newman RA, Gyllenhaal C. Impact of antioxidant supplementation on chemotherapeutic toxicity: a systematic review of the evidence from randomized controlled trials. Int J Cancer. 2008;123(6):1227-1239.

30. Mut-Salud N, Álvarez PJ, Garrido JM, Carrasco E, Aránega A, Rodríguez-Serrano F. Antioxidant intake and antitumor therapy: toward nutritional recommendations for optimal results. Oxid Med Cell Longev. 2016; 2016:6719534.

31. Greenlee H, Hershman DL, Jacobson JS. Use of antioxidant supplements during breast cancer treatment: a comprehensive review. Breast Cancer Res Treat. 2009;115(3):437-452.

32. Lawenda BD, Kelly KM, Ladas EJ, Sagar SM, Vickers A, Blumberg JB. Should supplemental antioxidant administration be avoided during chemotherapy and radiation therapy? J Natl Cancer Inst. 2008;100(11):773-783.

33. Yasueda A, Urushima H, Ito T. Efficacy and interaction of antioxidant supplements as adjuvant therapy in cancer treatment: A systematic review. Integr Cancer Ther. 2016;15(1):17-39.
Cancer Management and Research

\section{Publish your work in this journal}

Cancer Management and Research is an international, peer-reviewed open access journal focusing on cancer research and the optimal use of preventative and integrated treatment interventions to achieve improved outcomes, enhanced survival and quality of life for the cancer patient. The manuscript management system is completely online and includes

\section{Dovepress}

a very quick and fair peer-review system, which is all easy to use. Visit http://www.dovepress.com/testimonials.php to read real quotes from published authors. 